05

\title{
Магнитная структура разбавленных ферритов-гранатов
}

\author{
() Ю.Б. Кудасов, ${ }^{1}$ P.В. Козабаранов ${ }^{2}$ \\ ${ }^{1}$ Саровский фризико-технический институт, \\ Национальный исследовательский ядерный университет „МИФИ“, \\ Саров, Россия \\ ${ }^{2}$ Российский федеральный ядерный центр - \\ Всероссийский научно-исследовательский институт экспериментальной фризики, \\ Саров, Россия \\ E-mail: kudasov@ntc.vniief.ru
}

Поступила в Редакцию 15 апреля 2019 г.

В окончательной редакции 22 апреля 2019 г.

Принята к публикации 24 апреля 2019 г.

\begin{abstract}
Представлена модель магнитной структуры разбавленных ферритов-гранатов с немагнитными ионами в додекаэдрической подрешетке. Разбавление магнитных подрешеток железа предполагается избирательным: в предельном случае замещение железа немагнитными ионами происходит только в тетраэдрической подрешетке. В этом случае ионы железа в октаэдрическом окружении имеют переменное число ближайших магнитных соседей, поэтому вводятся октаэдрические подрешетки в зависимости от числа магнитных соседей. Показано, что такая модель хорошо описывает магнитные свойства разбавленных ферритов-гранатов с точкой компенсации.
\end{abstract}

Ключевые слова: магнитная структура, ферриты-гранаты, ферримагнетик, разбавленная структура, температура компенсации.

DOI: $10.21883 /$ FTT.2019.09.48103.06N

\section{1. Введение}

Благодаря уникальным магнитным и оптическим свойствам ферриты-гранаты нашли широкое применение в сверхвысокочастотной электронике и магнитооптических устройствах [1-3], также они представляют интерес для сверхбыстродействующих устройств записи и обработки информации $[4,5]$. Особенностью ферритовгранатов является возможность варьирования состава в широком диапазоне и получения твердых растворов с разнообразными магнитными и оптическими свойствами [6-8].

В настоящей работе обсуждаются ферриты-гранаты с немагнитными ионами, находящимися в додекаэдрическом окружении $\left(\mathrm{Y}^{3+}, \mathrm{Lu}^{3+}, \mathrm{Bi}^{3+}\right)$. В этом случае магнитную подсистему образуют ионы железа $\mathrm{Fe}^{3+}$ в состоянии с полным спином $S=5 / 2$ в двух кристаллографических позициях: октаэдрической (индекс $a$ ) и тетраэдрической (индекс $d$ ). Соотношение числа ионов в этих позициях составляет $\mathrm{Na}: \mathrm{Nd}=2: 3$.

На рис. 1 показана упрощенная структура ферритаграната. На нем видно, что пары ближайших соседей в октаэдрической и тетраэдрической позициях связаны через катион кислорода (общая вершина тетраэдров и октаэдров на рис. 1) с углом связи около $127^{\circ}$. Это приводит к сильному косвенному обменному взаимодействию, которое носит антиферромагнитный (АФМ) характер, вследствие чего такой феррит-гранат является двухподрешеточным ферримагнетиком [2]. Число ближайших соседей для ионов в двух подрешетках составляет $z_{a}=6$ и $z_{d}=4$. Как можно видеть из рис. 1 , пары ближайших ионов железа в одной и той же подрешетке находятся на значительном расстоянии пары тетраэдр-тетраэдр и октаэдр-октаэдр не имеют общих вершин, поэтому обменные взаимодействия внутри подрешеток, оказываются примерно на порядок слабее межподрешеточных [1].

Избирательное замещение ионов железа немагнитными ионами (например, $\mathrm{Ga}^{3+}, \mathrm{Al}^{3+}$ ) позволяет изменять отношение $\mathrm{Na}: \mathrm{Nd}$. Ионы галлия занимают, в основном, тетраэдрические позиции [6,7]. Степень избирательности сильно зависит от технологических факторов (темпера-

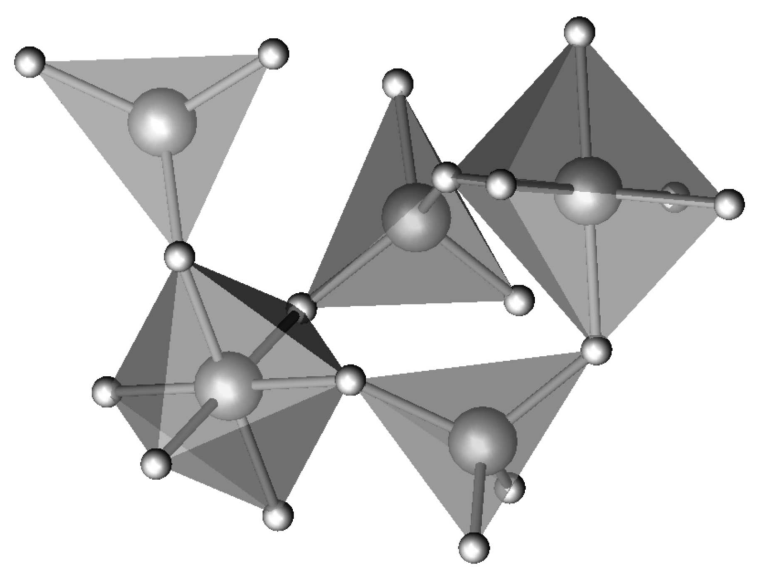

Рис. 1. Структура феррита-граната: ионы $\mathrm{Fe}^{3+}$ (большие сферы) в октаэдрическом и тетраэдрическом окружении катионов $\mathrm{O}^{2-}$ (малые сферы), додекаэдрические позиции не показаны. 
тура отжига, состав и т.д.). Можно добиться создания твердых растворов, в которых до 95\% замещенных галлием узлов находятся в тетраэдрической позиции [8]. Таким образом, разбавление происходит практически только в тетраэдрической подрешетке и при определенной концентрации достигается твердый раствор с точкой компенсации магнитных моментов [1,6,9-11]. Эти системы представляются перспективными с точки зрения практического использования $[9,10]$; в одной из них, $\left(\mathrm{Lu}_{1-x} \mathrm{Bi}_{x}\right)_{3}\left(\mathrm{Fe}_{1-y-z} \mathrm{Ga}_{y} \mathrm{Al}_{z}\right)_{5} \mathrm{O}_{12}$, недавно наблюдался необычный фазовый переход в точке компенсации [12].

Замещению ионов железа немагнитными ионами сопутствует возникновение беспорядка в магнитной подсистеме. В работе [13] обсуждались различные аспекты беспорядка в магнитной подсистеме, однако сведение к двухподрешеточной модели молекулярного поля приводит к следующему противоречию. Для феноменологического описания экспериментальных данных требуются параметры внутриподрешеточного молекулярного поля, близкие по величине к константе межподрешеточного обмена, но это противоречит микроскопическим представлениям об обменном взаимодействии в ферритахгранатах.

В настоящей работе изучается роль сильного беспорядка при формировании точки компенсации. Предложена многоподрешеточная модель разбавленных ферритовгранатов, которая раскрывает физические причины возникновения температурной компенсации магнитных моментов, снимает указанное выше противоречие и хорошо описывает наблюдаемые магнитные характеристики твердых растворов.

\section{2. Модель разбавленного феррита-граната}

Мы рассматриваем феррит-гранат с немагнитными ионами в додекаэдрическом окружении с идеальным избирательным замещением ионов железа немагнитными ионами только в тетраэдрической подрешетке. Предполагается также, что молекулярное поле между подрешетками определяется только ближайшими соседями. Молекулярное поле для ионов железа в октаэдрической подрешетке сильно зависит от числа ближайших магнитных соседей, которое является переменным в разбавленном соединении. Если замещение в тетраэдрической решетке происходит случайным образом (некоррелированно), то вероятность появления $l$ ближайших магнитных соседей для иона железа в октаэдрической позиции $p_{l}(k)$ определяется биномиальным распределением:

$$
p_{l}(k)=\frac{z_{a} !}{\left(z_{a}-l\right) ! l !} k^{l}(1-k)^{z_{a}-l},
$$

где $0 \leq k \leq 1$ - доля магнитных ионов в тетраэдрической позиции, индекс $l$ принимает целые значения от 0 до 6 и $\sum_{l} p_{l}(k)=1$.
Сгруппируем ионы в октаэдрическом окружении в подрешетки в зависимости от числа ближайших магнитных соседей. Тогда молекулярные поля для семи октаэдрических подрешеток $\left(\mathbf{H}_{a l}\right)$ и тетраэдрической подрешетки $\left(\mathbf{H}_{d}\right)$ можно представить в виде

$$
\begin{gathered}
\mathbf{H}_{a l}=\mathbf{H}+\lambda_{a d l} \mathbf{M}_{d}+\lambda_{a a} \sum_{l=0}^{z_{a}} \mathbf{M}_{a l}, \\
\mathbf{H}_{d}=\mathbf{H}+\lambda_{d a} \sum_{l=0}^{z_{a}} A_{l} \mathbf{M}_{a l}+\lambda_{d d} \mathbf{M}_{d},
\end{gathered}
$$

где $A_{l}=l\left[\sum_{m=0}^{z_{a}} m p_{m}(k)\right]^{-1}, \mathbf{H}$ - внешнее магнитное поле, $\lambda$ - коэффициенты молекулярного поля. Магнитные моменты октаэдрических подрешеток имеют вид

$$
M_{a l}(T)=M_{a}(0) B_{S}\left(x_{a l}\right) p_{l}(k),
$$

где $M_{a}(0)$ - магнитный момент неразбавленной октаэдрической подрешетки, $x_{a l}=g \mu_{B} S H_{a l} /\left(k_{B} T\right), B_{S}$ - функция Бриллюэна, $g=2-g$-фактор, $\mu_{B}-$ магнетон Бора, $S=5 / 2, k_{B}$ - постоянная Больцмана, $T-$ температура. Для тетраэдрической подрешетки, как обычно [2],

$$
M_{d}(T)=M_{d}(0) B_{S}\left(x_{d}\right),
$$

где $x_{d}=h \mu_{B} S H_{d}\left(k_{B} T\right)$. В настоящей работе мы учитываем обмен только между ближайшими соседями в октаэдрической и тетраэдрической позициях, пренебрегая внутриподрешеточными взаимодействиями $\left(\lambda_{a a}=\lambda_{d d}=0\right)$. Оставшиеся коэффициенты выражаются через обменный интеграл в паре ближайших соседей $J<0$ как

$$
\lambda_{d a}=\frac{J z_{d}}{g^{2} \mu_{B}^{2} n_{a}}, \quad \lambda_{a d l}=\frac{J}{g^{2} \mu_{B}^{2} n_{d}} l,
$$

где $n_{a}$ и $n_{d}-$ концентрации ионов в подрешетках в неразбавленном феррите-гранате (например, в $\mathrm{Y}_{3} \mathrm{Fe}_{5} \mathrm{O}_{12}$ ).

Коэффициенты $A_{l}$ в выражении (2) появляются в связи с тем, что в зависимости от числа ближайших магнитных соседей ионы октаэдрических подрешеток вносят различный вклад в молекулярное поле. Эти коэффициенты обеспечивают выполнение третьего закона Ньютона для магнитных взаимодействий между тетраэдрической и октаэдрическими подрешетками. Отметим также, что, выражая полное число пар ближайших соседей в разбавленной решетке через концентрацию и координационное число, мы получаем условие

$$
\left(k n_{d}\right) z_{d}=n_{a}\left(\sum_{l=0}^{z_{z}} l p_{l}(k)\right) .
$$

Всюду ниже мы используем значение обменного интеграла $J$, найденного из температуры Нееля для неразбавленного феррита-граната $\left(\mathrm{Y}_{3} \mathrm{Fe}_{5} \mathrm{O}_{12}\right)$, поэтому в модели остается один свободный параметр - доля 
ионов железа в тетраэдрической подрешетке $k$. В предельном случае неразбавленного феррита-граната $k \rightarrow 1$, под знаком суммы в (2) остается только одно слагаемое $l=6$ и мы приходим к обычной двухподрешеточной модели. Заметим также, что ионы с $l=0$ не имеют магнитных соседей и фактически представляют собой парамагнитные примеси.

\section{3. Результаты расчетов и обсуждение}

На рис. 2 представлена расчетная зависимость температуры магнитного момента разбавленного соединения при $k=0.664$, что соответствует температуре компенсации, равной примерно $55 \mathrm{~K}$. При низкой температуре доминирует магнитный момент октаэдрической подрешетки, а при высокой - тетраэдрической, что соответствует наблюдаемому поведению растворов $\mathrm{Y}_{3}\left(\mathrm{Fe}_{2-x} \mathrm{Ga}_{x}\right)\left(\mathrm{Fe}_{3-y} \mathrm{Ga}_{y}\right) \mathrm{O}_{12}$ [6]. Этот факт имеет очевидное физическое объяснение в рамках многоподрешеточной модели: октаэдрические подрешетки с малыми $l$ находятся в слабом молекулярном поле, поэтому в них разупорядочение с повышением температуры происходит значительно быстрее, чем в тетраэдрической подрешетке. Это приводит к относительно быстрому уменьшению суммарного магнитного момента октаэдрических подрешеток и к переходу через точку температурной компенсации. Подрешетка с $l=0$ оказывается изолированной парамагнитной примесью.

В работе [13] также принимался во внимание сильный разброс эффективных магнитных полей ионов железа в октаэдрических позициях. Однако, окончательно результат интерпретировался в рамках двухподрешеточной модели как изменение коэффициентов молекулярного поля. В этом случае $\lambda_{a d}=\lambda_{d a}$ и молекулярные поля на тетраэдрической и октаэдрической подрешетках оказываются равными при нулевом внешнем поле. Тогда при рассмотрении взаимодействия только между октаэдрической и тетраэдрической подрешетками температурную компенсацию получить вообще невозможно, поскольку ионы железа в одинаковом состоянии $S=5 / 2$ находятся в одинаковом молекулярном поле и должны иметь одинаковую температурную зависимость магнитных моментов. В двухподрешеточной модели компенсация достигается за счет введения сильного молекулярного поля внутри подрешеток, сравнимого с $\lambda_{a d}[6,14]$, что противоречит утверждению о слабости внутриподрешеточных взаимодействий [1], которое вытекает из структуры ферритовгранатов (рис. 1).

При сравнении расчетных зависимостей магнитного момента с экспериментальными значениями (рис. 2) следует иметь в виду тот факт, что всегда имеется небольшое замещение ионов железа и в октаэдрической подрешетке, что приводит к уменьшению моментов подрешеток и полного магнитного момента, а также к снижению температуры Нееля твердого раствора. Поэтому согласие расчетных и экспериментальных данных является удовлетворительным.

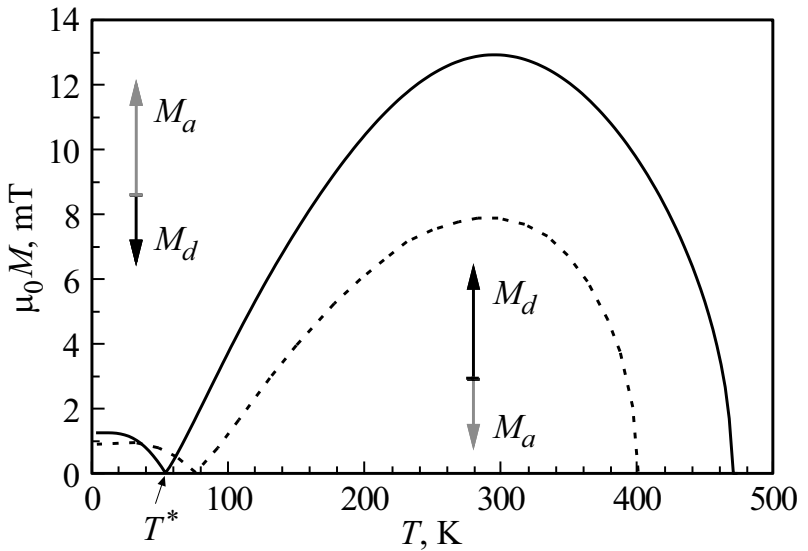

Рис. 2. Магнитный момент разбавленного феррита-граната как функция температуры: сплошная линия - расчетная при $k=0.664$, пунктирная - по экспериментальным данным работы [6] для твердого раствора $\mathrm{Y}_{3}\left(\mathrm{Fe}_{2-x} \mathrm{Ga}_{x}\right)\left(\mathrm{Fe}_{3-y} \mathrm{Ga}_{y}\right) \mathrm{O}_{12}$. Температура компенсации отмечена как $T^{*}$.

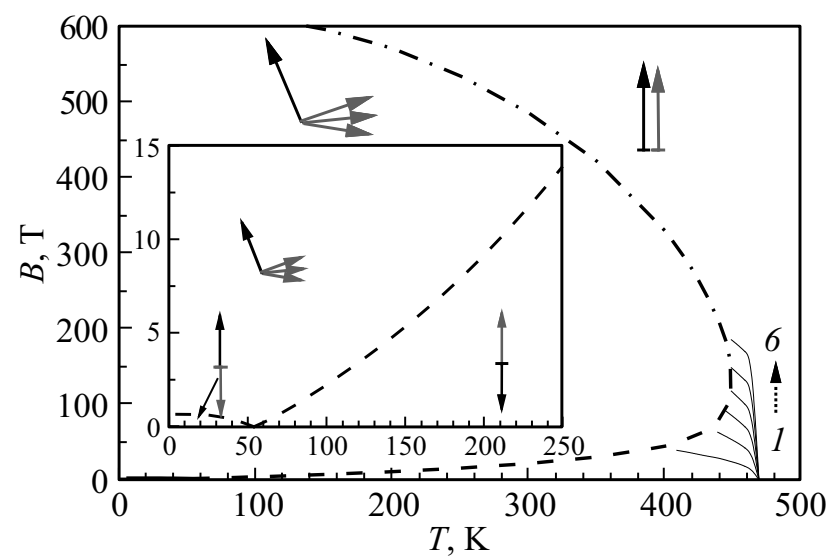

Рис. 3. Магнитная фазовая диаграмма разбавленного ферритаграната $(k=0.664)$. Пунктирная и штрихпунктирная линии ограничивают область угловой фазы, сплошные линии - фазовые переходы первого рода (опрокидывание октаэдрических подрешеток с $l$ от 1 до 6). На вставке показан увеличенный фрагмент диаграммы при низких магнитных полях. Черными и серыми стрелками в поле рисунка схематично показаны направления магнитных моментов подрешеток.

На рис. 3 построена магнитная фазовая диаграмма, которая в целом сходна с диаграммой для двухподрешеточной модели. На вставке показана область вблизи температуры компенсации (около $50 \mathrm{~K}$ ). Следует отметить, что критические магнитные поля фазовых переходов первого рода для октаэдрических переходов различаются, поэтому вместо одного перехода возникает последовательность таких переходов. Число переходов равно шести, поскольку подрешетка с $l=0$ является парамагнитной. Так как при высокой температуре эти переходы будут сильно размытыми, их экспериментальное наблюдение представляется проблематичным. Отметим также, что в угловой фазе магнитные моменты окта- 
эдрических подрешеток ориентированы непараллельно друг другу и образуют „веер“, как схематично показано на рис. 3.

\section{4. Заключение}

В работе представлена многоподрешеточная модель молекулярного поля для разбавленных ферритов-гранатов с немагнитными ионами в додекаэдрических позициях. Кроме константы обменного взаимодействия между ближайшими соседями, которая определяется по температуре Нееля неразбавленного иттриевого ферритаграната, в модель входит единственный параметр доля магнитных ионов в тетраэдрической подрешетке $k$. Показано, что температурная компенсация является следствием сильного беспорядка в магнитной системе: температурные зависимости магнитного момента ионов железа в октаэдрических позициях с различным количеством ближайших соседей сильно различаются, что приводит к относительно быстрому уменьшению суммарного магнитного момента октаэдрической подрешетки. В целом предлагаемый механизм аналогичен механизму компенсации магнитного момента в ферритах-гранатах с магнитным редкоземельным ионом в додекаэдрической позиции [2]: додекаэдрическая подрешетка слабо связана с подрешетками железа и поэтому быстро разупорядочивается с ростом температуры. В разбавленных системах, рассмотренных выше, роль дополнительной слабо связанной подрешетки выполняют октаэдрические подрешетки с малыми значениями $l$.

В традиционной двухподрешеточной модели молекулярного поля $[6-8,13]$ разбавленных ферримагнетиков обе железные подрешетки оказываются абсолютно идентичными: константы молекулярного поля для взаимодействия между подрешетками должны быть равными $\left(\lambda_{a d}=\lambda_{d a}\right)$, и ионы железа в обоих позициях находятся в одном и том же состоянии $S=5 / 2$. Тогда температурная компенсация достигается только за счет предположения о сильном внутриподрешеточном обменном взаимодействии, сравнимом с межподрешеточным, которое является нефизичным поскольку противоречит результатам микроскопической теории.

Наблюдаемое незначительное количественное расхождение с экспериментальными данными связано с тем, что в реальных твердых растворах некоторое замещение ионов железа происходит не только в тетраэдрической, но и в октаэдрической подрешетке.

\section{Финансирование работы}

Работа выполнена при поддержке Российского фонда фундаментальных исследований (региональный проект № 18-48-520006).

\section{Конфликт интересов}

Авторы заявляют, что у них нет конфликта интересов.

\section{Список литературы}

[1] A.K. Zvezdin, V.A. Kotov. Modern magnetooptics and magnetooptical materials. Institute of Physics Publishing, Bristol and Philadelphia (1997). 381 p.

[2] В.А. Боков. Физика магнетиков. Невский диалект, СПб (2002). $271 \mathrm{c}$.

[3] L. Bi, J. Hu, P. Jiang, H.S. Kim, D.H. Kim, M.C. Onbasli, G.F. Dionne, C.A. Ross. Materials 6, 5094 (2013).

[4] M. Deb, M. Vomir, J.-L. Rehspringer, J.-Y. Bigot. Appl. Phys. Lett. 107, 252404 (2015).

[5] A. Stupakiewicz, K. Szerenos, D. Afanasiev, A. Kirilyuk, A.V. Kimel. Nature 542, 71 (2017).

[6] P. Hansen, P. Röschmann, W. Tolksdorf. J. Appl. Phys. 45, 2728 (1974).

[7] L.E. Helseth, R.W. Hansen, E.I. Il'yashenko, M. Baziljevich, T.H. Johansen. Phys. Rev. B 64, 174406 (2001).

[8] P. Röschmann, P. Hansen. J. Appl. Phys. 52, 6257 (1981).

[9] A.K. Zvezdin. In: Handbook of Magnetic Materials. / Ed. K.H.J. Buschow. Elsevier Science (1995). V. 9. 405 c.

[10] Н.А. Логинов, М.В. Логунов, В.В. Рандошкин. ФТТ 31, 10, 58 (1989).

[11] В.В. Волков, В.А. Боков. ФТТ 50, 193 (2008)

[12] Ю.Б. Кудасов, М.В. Логунов, Р.В. Козабаранов, И.В. Макаров, В.В. Платонов, О.М. Сурдин, Д.А. Маслов, А.С. Коршунов, Е.Я. Попов, А.С. Светлов. ФТТ 60, 11, 2166 (2018).

[13] G.F. Dionne. J. Appl. Phys. 85, 4627 (1999).

[14] P. Novák. 4.1.2.1.2 Molecular-field- and exchange constants. Landolt-Börnstein- Group III Condensed Matter (Numerical Data and Functional Relationships in Science and Technology). V. 27e. Springer, Berlin, Heidelberg (1991).

Редактор Е.Ю. Флегонтова 